\title{
E-LEARNING BERBASIS TELEGRAM BOT
}

\author{
I Putu Gede Abdi Sudiatmikal, Komang hari Santhi Dewi ${ }^{2}$ \\ ITB STIKOM BALI ${ }^{1,2}$ \\ gede_abdi@stikom-bali.ac.id', santhi.dewi@stikom-bali.ac.id
}

\begin{abstract}
Technology today has helped a lot in the implementation of learning in the world of education. Technology is often used in learning to help facilitate the implementation of learning. There are several obstacles in the face-to-face learning process such as the slow attendance recapitulation process because it still uses paper forms and difficulty accessing important information because it is conveyed orally. The development of a learning system using the help of electronic devices can be called e-learning, which can be a solution to solving problems in the face-to-face learning process. Seeing the high number of smartphone users also has an impact on the high access to applications in it. The telegram application is a cloud-based instant messaging service which can be developed to generate chatbots. Chatbot is an application that can help to automatically answer some of the questions submitted by users. Thus, a website-based E-learning system research with Telegram Bot was conducted. Telegram Bot was chosen because of the free access by the API of the Telegram Bot. The purpose of this research is to design and build a website-based e-learning system with a telegram bot. Making a telegram chatbot to overcome problems in the learning process such as knowing grades, collecting assignments and sending assignments. Telegram bot will help educators to speed up the transfer of knowledge to students. The application of the Waterfall model was chosen because this method is applicable and the stages are carried out sequentially. The first stage of the requirements is data collection, followed by the design stage to design the architecture and appearance of the system, then the implementation of the code processing stage and ends with verification to check all features to match expectations. This research produces a system using two platforms, a telegram chatbot and a website-based admin system. The telegram chatbot has features for lecturers to upload material or
\end{abstract}

\begin{tabular}{|c|c|}
\hline Article History & ABSTRAK \\
\hline $\begin{array}{l}\text { Received 2020-08-06 } \\
\text { Revised 2020-08-24 } \\
\text { Accepted 2020-08-28 }\end{array}$ & $\begin{array}{l}\text { Teknologi dewasa ini telah banyak membantu penyelenggaraan } \\
\text { pembelajaran di dunia Pendidikan. Teknologi sering kali digunakan pada } \\
\text { pembelajaran untuk membantu mempermudah penyelenggaraan } \\
\text { pembelajaran.. Adanya beberapa kendala dalam proses belajar tatap muka }\end{array}$ \\
\hline Key words & $\begin{array}{l}\text { seperti, lambatnya proses rekapitulasi absensi karena masih menggunakan } \\
\text { form kertas dan kesulitan mengakses informasi penting karena }\end{array}$ \\
\hline $\begin{array}{l}\text { Chatbot, E-learning, } \\
\text { Telegram, Waterfall }\end{array}$ & $\begin{array}{l}\text { disampaikan secara lisan. Pengembangan sistem pembelajaran dengan } \\
\text { menggunakan bantuan perangkat elektronik bisa disebut dengan e- } \\
\text { learning, dapat menjadi solusi dalam menyelesaikan kendala proses } \\
\text { belajar tatap muka. Melihat tingginya pengguna smartphone berdampak } \\
\text { juga terhadap tingginya akses aplikasi didalamnya. Aplikasi telegram } \\
\text { merupakan layanan pesan instan berbasis cloud dimana dapat } \\
\text { dikembangkan untuk menghasilkan chatbot. Chatbot merupakan sebuah } \\
\text { aplikasi yang dapat membantu untuk menjawab secara otomatis beberapa } \\
\text { pertanyaan yang di ajukan oleh pengguna.. Dengan demikian dilakukanlah } \\
\text { penelitian Sistem E-learning berbasis Website dengan Telegram Bot. } \\
\text { Telegram Bot di pilih karena akses yang gratis oleh API dari Telegram } \\
\text { Bot. Tujuan dari penelitian ini untuk merancang serta membangun suatu } \\
\text { sistem e-learning berbasis website dengan telegram bot. Pembuatan } \\
\text { chatbot telegram untuk mengatasi kendala proses pembelajaran seperti } \\
\text { mengetahui nilai, mengumpulkan tugas dan mengirimkan tugas. Telegram } \\
\text { bot akan membantu pengajar untuk mempercepat transfer ilmu kepada } \\
\text { peserta didik. Penerapan model Waterfall dipilih, karena metode ini } \\
\text { bersifat aplikatif dan tahapannya dilakukan secara berurutan. Tahap } \\
\text { pertama requirement dilakukan pengumpulan data, dilanjutkan tahap }\end{array}$ \\
\hline
\end{tabular}




\begin{abstract}
design untuk merancang arsitektur dan tampilan sistem, kemudian implementation tahap pengerjaan kode dan diakhiri dengan verification untuk memeriksa semua fitur agar sesuai harapan. Penelitian ini menghasilkan sistem dengan menggunakan dua platform, chatbot telegram dan sistem admin berbasis website. Chatbot telegram memiliki fitur bagi dosen untuk mengunggah materi atau pengumuman, mengunggah tugas, dan mengunduh jawaban dari mahasiswa. Bagi mahasiswa dapat mengunduh materi, mengunduh tugas, mengunggah jawaban serta melihat list pengumuman. Sistem admin memiliki fitur untuk mengelola data user (mahasiswa dan dosen), melihat dan menghapus materi pelajaran, tugas, jawaban serta mengelola pengumuman. Berdasarkan hasil pengujian sistem menggunakan metode test aplikasi blackbox testing diperoleh hasil yang sesuai rencana pada seluruh fitur sistem.
\end{abstract}

\title{
PENDAHULUAN
}

Pendidikan adalah interaksi antara pendidik dan peserta didik. Interaksi bisa dengan bertukar ilmu pengetahuan. Proses interaksi biasanya terjadi di dalam kelas. Guru atau pendidik akan memberikan pengetahuan secara dua arah dan ditangkap oleh psesrta didik yang akan memberikan sebuah umpan bali. Pendidikan dewasa ini mengarah kepada metode keaktifan peserta didik untuk mendapatkan dan mengenali proses pembelajaran yang ada. Pengetahuan di dapat oleh siswa tidak hanya di peroleh dari interaksi dengan guru saja melainkan juga interaksi dengan teman kelas [1].

Menjalankan proses belajar mengajar dilakukan di ruang kelas dimana pembelajaran adalah usaha seorang pendidik untuk mengarahkan siswanya mendapatkan ilmu sesuai dengan sumber belajar yang sudah di rencanakan terlebih dahulu [2]. Proses pembelejaran adalah bagaimana meningkatkan pengetahuan dari seorang peserta didik dari adanya interaksi yang dibangun oleh pendidik.Pada tahapan Pendidikan formal pendidik akan memberikan pengetahuan kepada peserta didik terukur dan terarah.[3]. Pendidikan formal mengacu pada pendidikan di sekolah yang diperoleh secara teratur, sistematis, bertingkat, dan dengan mengikuti syarat-syarat yang jelas[2].

Banyak kegiatan di dalam kelas saat ini masih dijalankan secara manual melihat dari banyaknya lembaga pendidikan yang menggunakan berbagai prosedur mengajar secara tradisional seperti, absensi murid dengan form kertas dan memberikan informasi mengenai proses belajar secara lisan. Selain itu kadangkala disaat pengajar berhalangan hadir dapat membuat penyampain materi menjadi terhambat dan target pemahaman suatu pelajaran tidak tercapai. Ini tentu menjadi kekurangan dimana lembaga pendidikan seharusnya dapat memanfaatkan berbagai teknologi yang ada sehingga kendala di atas dapat ditangani.[4]

Melihat banyaknya penggunaan gadget seperti smartphone yang diperkirakan mencapai 100 juta pengguna lebih di Indonesia pada tahun 2018 [5] selain itu pengguna internet yang mencapai 123 juta orang [6] dengan jumlah penduduk 256 juta jiwa [7] tentu menjadi sebuah acuan dimana pembuatan aplikasi mobile kemungkinan besar akan semakin berkembang dan semakin banyak diakses, dengan ini pembutan sistem berbasis mobile menjadi pilihan tepat untuk mengembangkan suatu media yang mudah dijangkau dan dapat diakses dimana saja. Tidak hanya membuat dari awal kita bisa memanfaatkan aplikasi mobile dan mengemasnya menjadi suatu sistem baru agar bisa dimanfaatkan dan digunakan bagi pengajar maupun peserta didik.

Telegram merupakan layanan pesan instan berbasis cloud yang sudah menjadi sarana komunikasi bagi semua kalangan, kemudahan dan kecepatan dalam pengiriman pesan menjadi keunggulan yang sangat membantu masyarakat luas sehingga telegram memiliki jumlah pengguna cukup besar. Selain digunakan untuk sarana pengiriman pesan kita juga dapat mengembangkan sistem menggunakan fitur bot (akun Telegram yang dioperasikan oleh program).[8] 
Penelitian ini menggunakan telegram BOT karena API yang ditawarkan oleh telegram bersifat open source mempermudah pengembang untuk mengembangkan Bot sesuai dengan keinginan pengembang. [9].

\section{TINJAUAN PUSTAKA}

Definisi E-learning

Secara garis besar E-learning terdiri dari 2 kata, yaitu electronic dan learning yang artinya membawa konsep pembelajaran ke dunia elektornik. Bisa di katakana konsep e-learning menawarkan sebuah metode pembelajaran dengan menggunakan media online. Media online saat ini sering kali dimanfaatkan oleh pendidik untuk mempermudah proses pembelajaran dikelas[10]. Konsep e-learning memberikan proses pembelajaran bisa dilakukan oleh siapapun, dimanapun dan kapanpun. E-learning telah membawa paradigma perubahan pada konsep pembelajaran yang bisa menggunakan perantara website atau media online. Elearning telah membawa konsep sebuah kelas menjadi kearah dunia yang lebih luas [11].

\section{Website}

Website merupakan salah satu sumber daya dari internet. Halaman pada sebuah situs website Website merupakan halaman situs yang dibuat dengan pendekatan Hyperlink dimana seseorang akan mendapatkan informasi dari lompat. Website mulai dikenal di Indonesia sekitar tahun 1998, dimana hanya perusahaan besar saja yang mampu memilikinya. Pada saat itu, website merupakan sebuah teknologi yang cukup mahal untuk dimiliki. Website dewasa ini sudah menjadi kebutuhan yang sangat penting di setiap industry[12]. Pengusaha sekarang banyak yang memasarkan produk yang dimilikinya dengan bantuan website

Website membutuhkan subskripsi (data masukan) agar para user bisa mengakses sebagaian atau keseluruhan isi website tersebut. Contohnya, ada beberapa situs-situs e-mail gratis, yang membutuhkan subskripsi agar kita bisa mengakses situs tersebut [13].

\section{Chatbot}

Chatbot (juga dikenal sebagai talkbot, chatterbot, Bot, IM bot, agen interaktif, atau Artificial Conversational Entity) adalah sebuah aplikasi yang dapat membantu untuk menjawab secara otomatis beberapa pertanyaan yang di ajukan oleh pengguna[10]. Chatbot biasanya digunakan dalam sistem dialog untuk berbagai tujuan praktis termasuk layanan pelanggan atau perolehan informasi. Beberapa chatbot menggunakan pendekatan yang dapat mendeksi kebiasaan pengguna dalam menggunakan kosa kata. Chatbot yang paling sederhana biasana hanya mencari kata kunci dan jawaban yang ada pada database.[14]

Istilah "ChatterBot" awalnya diciptakan oleh Michael Mauldin (pencipta Verbot pertama, Julia) pada tahun 1994 untuk menggambarkan program percakapan ini. Saat ini, sebagian besar chatbot dapat diakses melalui asisten virtual seperti Google Assistant dan Amazon Alexa, melalui aplikasi perpesanan seperti Facebook Messenger atau WeChat, atau melalui aplikasi dan situs web masing-masing organisasi [9].

\section{Model Waterfall}

Metode Waterfall merupakan metode pengembangan perangkat lunak yang terstuktur yang tersusun dari beberapa stage atau Langkah-langkah. Setiap Langkah harus di selesaikan sebelum nantinya menuju kelangkah selanjutnya. Metode waterfall merupakan metiode yang paling awal digunakan dalam membuat sebuah perangkat lunak[15] Metode Waterfall dimulai dari proses perencanaan, analisa, desain, dan implementasi pada sistem. Metode ini dilakukan dengan pendekatan yang sistematis, mulai dari tahap kebutuhan sistem lalu menuju ke tahap analisis, desain, coding, testing/verification, dan maintenance. Disebut waterfall karena setiap Langkah demi Langkah harus diselesaikan dan berjalan secara beruruturan[16]

\section{METODE}


Metode yang digunakan dalam pengembangan Sistem E-learning Berbasis Website Dengan Telegram Bot adalah Metode Waterfall yang secara garis besar dapat disimpulkan memiliki tahapan-tahapan berikut:

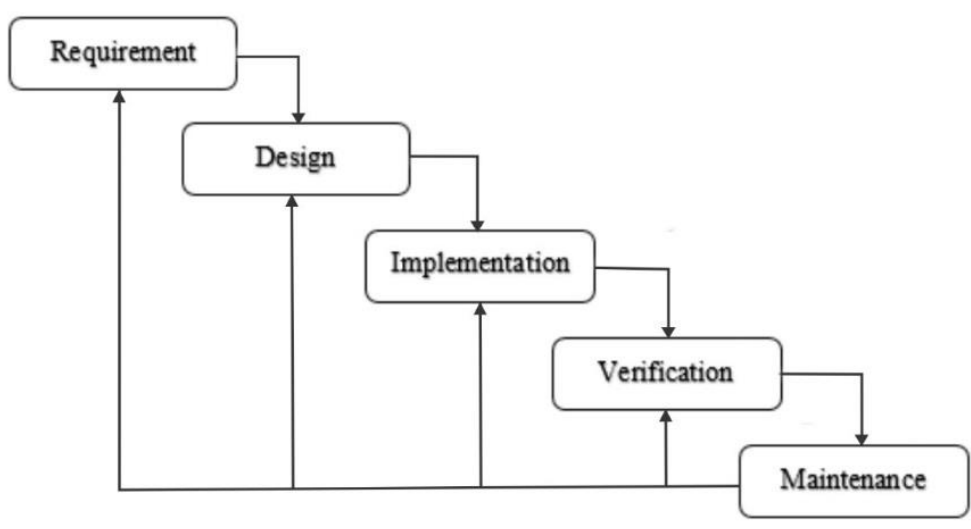

Gambar 1 Metode Waterfall

\section{Requirment}

Mengumpulkan apa yang dibutuhkan oleh calon pengguna sistem. Berarti mengumpulkan informasi dari pihak calon pengguna, menanyakan fungsi-fungsi apa yang diharapkan dan data apa saja yang akan diproses dalam dalam sistem nantinya. Untuk membuat e-learning dengan chatbot penulis mengumpulkan beberapa data seperti data pertanyaan pendididik, data dari proses pembelajaran dikelas, data dari metode penilaian dan pembelajaran dikelas.

\section{Impementation}

Mulai mengerjakan kode program sesuai dengan data yang didapatkan dan juga mengikuti rancangan desain sistem. Menggunakan bahasa pemrograman php untuk membangun sistem didukung framework untuk kerapian dan efisiensi kode program. Basis data sistem diimplementasikan dengan mysql, bahasa sql menjadi penghubung antara basis data dengan sistem. Telegram memiliki API untuk pengembangan bot sehingga lebih mudah dalam pengembangan, dengan ini dalam pengkodean chatbot e-learning dapat menggunakan fitur-fitur dari API telegram.

\section{Verification}

Tahap ini melakukan testing dari segala aspek fitur-fitur yang ada, mulai dari seluruh fitur chatbot e-learning dan sistem website admin. Jika ditemukan bug, dilakukan identifikasi kembali untuk mencari bagian mana yang perlu dibenahi. Pembuatan rencana pengujian menjadi patokan saat melaksanakan testing sistem. Proses verifikasi dilakukan denghan cara mencoba aplikasi ke pengguna kemudian dengan berbagai testing akan diperoleh bug dan proses pengembangan software kedepannya.

\section{Diagram Konteks}

Diagram konteks adalah data flow diagram tingkat atas (DFD Top Level). Yaitu diagram yang menggambarkan aliran-aliran data ke dalam dan keluar sistem atau keluar entitas eksternal[17]. Diagram konteks menggambarkan sistem dalam satu lingkaran dan hubungan dengan entitas luar. Diagram konteks dari website admin sistem e-learning berbasis website dapat dilihat pada Gambar 2. 


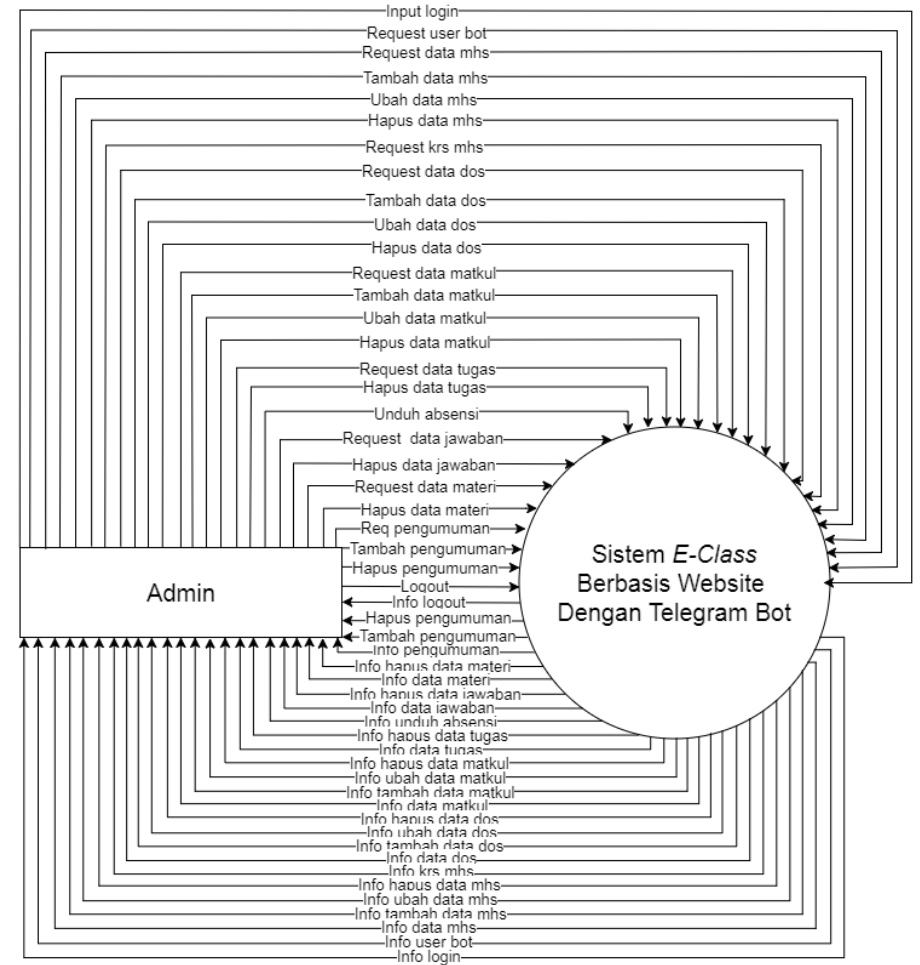

Gambar 1 Diagram Konteks

\section{Diagram Level 0}

Pada Gambar 4.2 diatas DFD level nol menggambarkan internal sistem secara global, yang dipecah dari diagram konteks sebelumnya menjadi sepuluh proses yaitu login, user bot, mahasiswa, dosen, matakuliah, materi, tugas, jawaban, pengumuman dan logout.

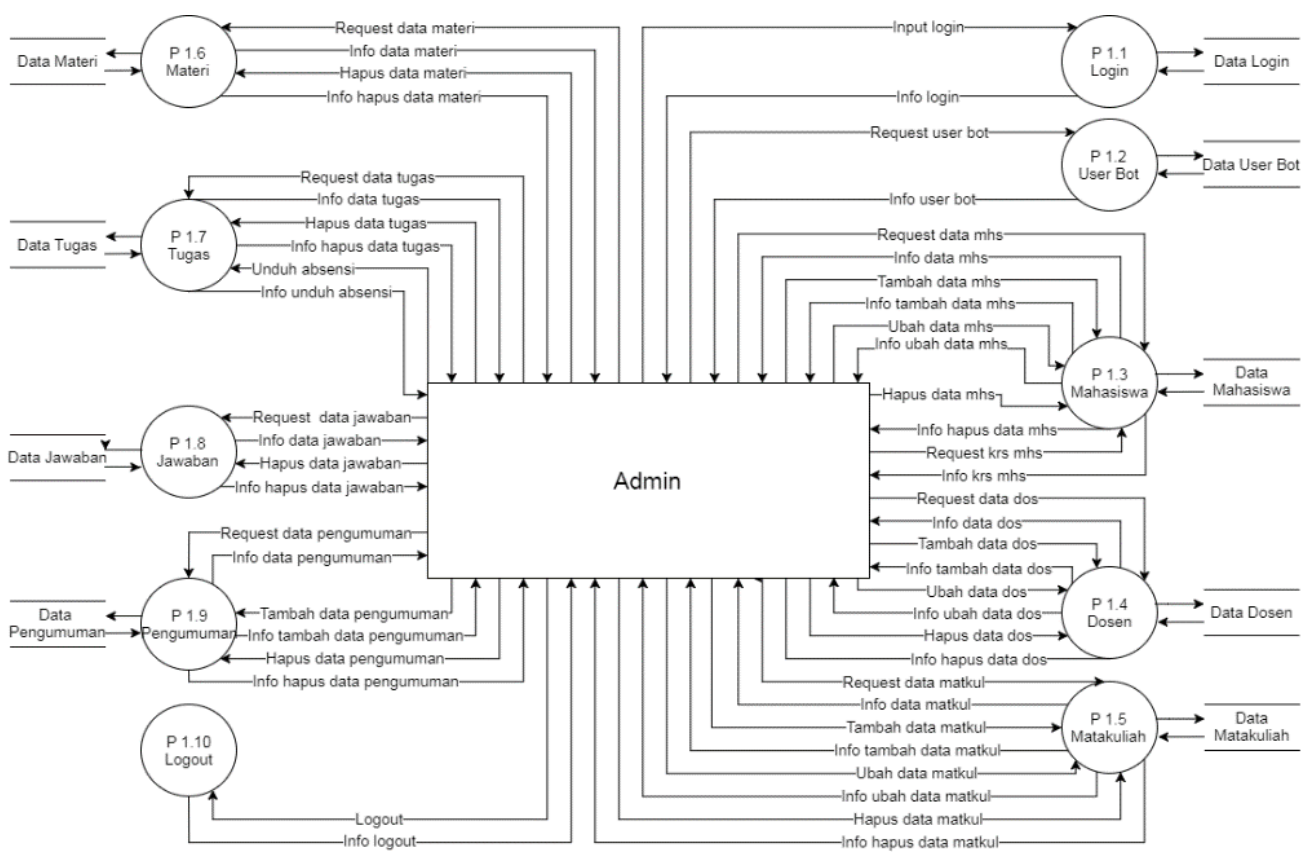




\section{Use Case Diagram}

Dalam Gambar 4 terlihat ada dua actor yaitu mahasiswa dan dosen. Saat ingin berinteraksi dengan sistem bot hal pertama yang dilakukan adalah melakukan registrasi, setelah itu semua fitur bot dapat diakses.

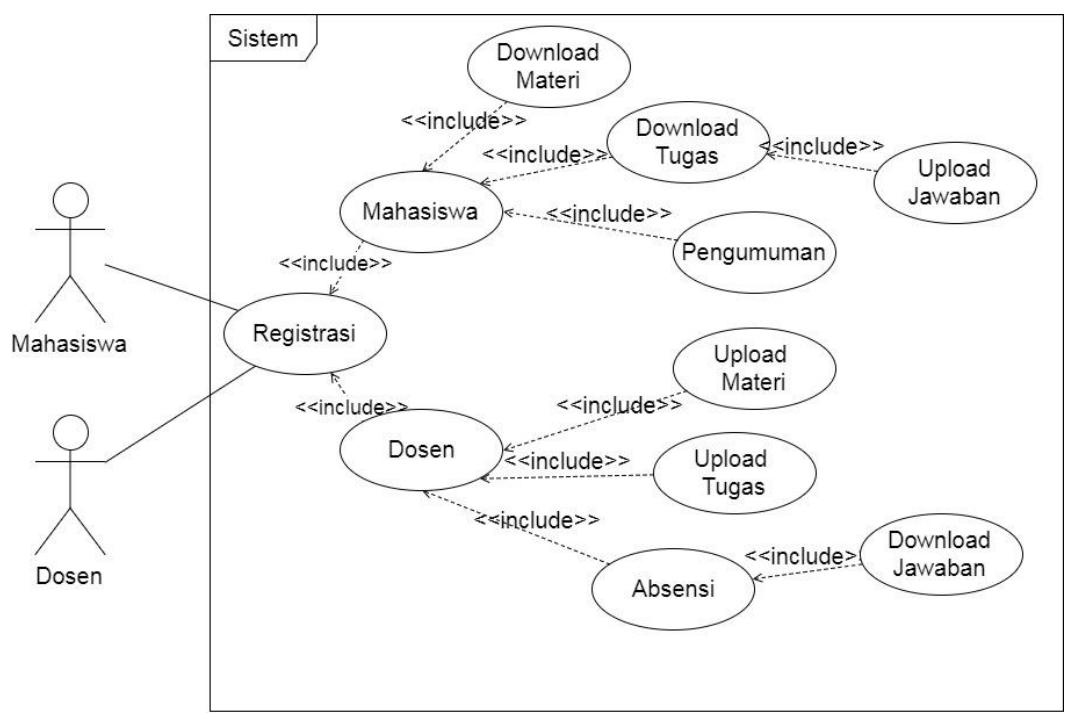

Gambar 3 Use Case Diagram

\section{Entity Relationship Diagram (ERD)}

Entity Relationship Diagram (ERD) merupakan model konseptual yang menggambarkan susunan data yang disimpan dalam sistem dan juga digunakan untuk memodelkan struktur data serta hubungan antar data. Dapat dilihat pada Gambar 5 merupakan gambaran ERD pada Sistem E-learning Berbasis Website Dengan Telegram Bot.

\section{Perancangan Antarmuka}

Pada Gambar 6 adalah rancangan antarmuka dashboard yang dapat diakses oleh admin. Dalam dashboard ada beberapa tampilan yang tersedia diantaranya jumlah user bot, dosen, mahasiswa, matakuliah dan lainnya.

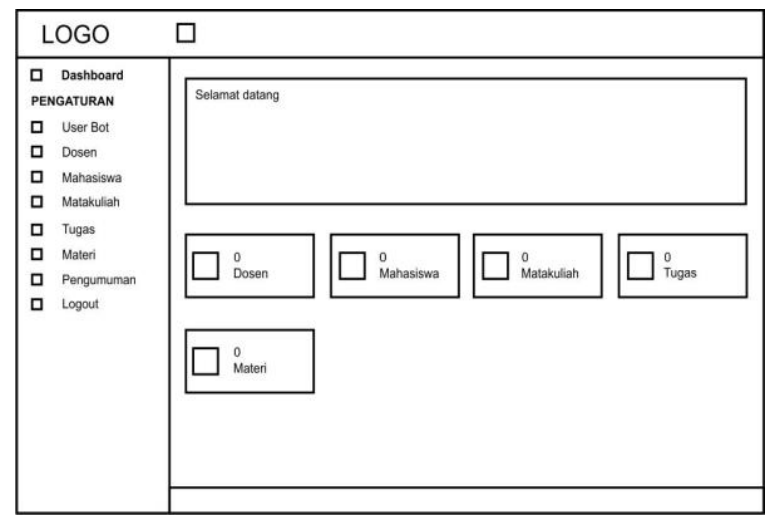

Gambar 4 Rancangan Antarmuka Beranda 


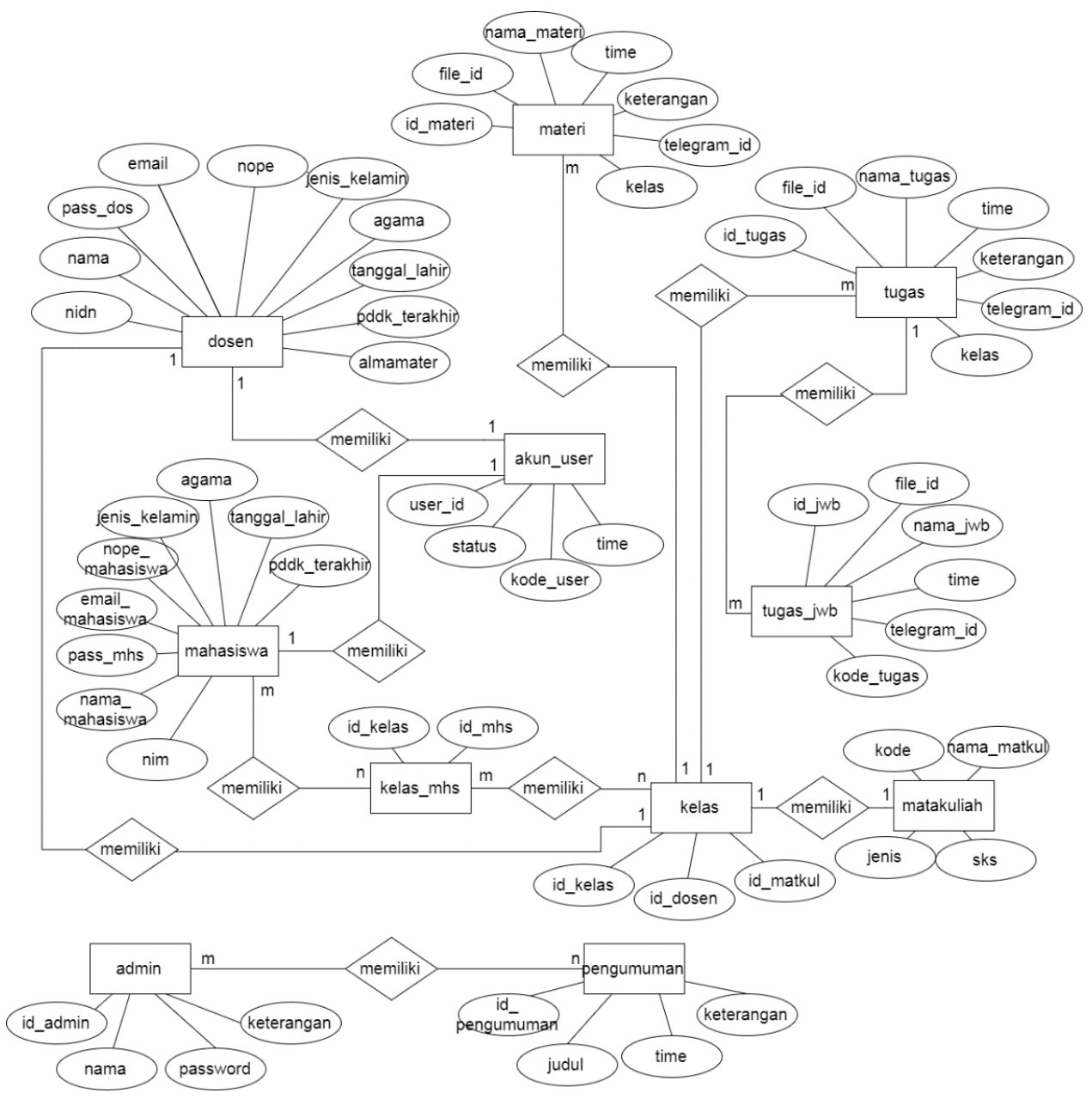

Gambar 5 Entity Relationship Diagram (ERD)

\section{Rancangan Antarmuka Registrasi}

Pada Gambar 7 adalah rancangan antarmuka registrasi, user memilih registrasi sebagai dosen atau mahasiswa agar dapat menggunakan fitur-fitur sistem bot.

\section{E E-learning Bot}

Halo... Selamat datang di bot E-class!

Silahkan lakukan registrasi sebagai:

(2) Ketik pesan...

Dosen

Mahasiswa

Gambar 6 Rancangan Antarmuka Registrasi 


\section{Rancangan Antarmuka Fitur-fitur Dosen}

Pada Gambar 8 adalah rancangan antarmuka fitur-fitur dosen, ditampilkan fitur dosen yaitu upload materi, upload tugas serta absensi.

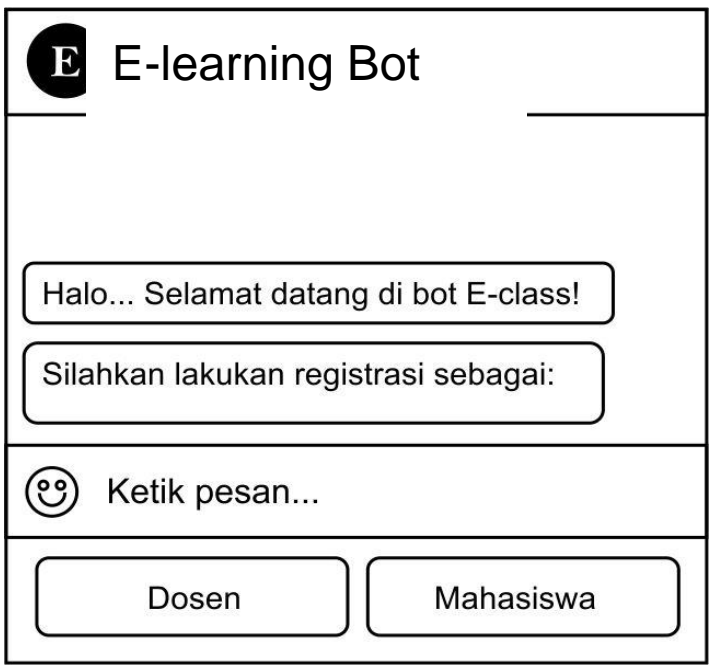

Gambar 7 Rancangan Antarmuka Fitur-fitur Dosen

\section{Rancangan Antarmuka Fitur-fitur Mahasiswa}

Pada Gambar 9 adalah rancangan antarmuka fitur-fitur mahasiswa, ditampilkan fitur mahasiswa yaitu download materi, download tugas serta pengumuman.

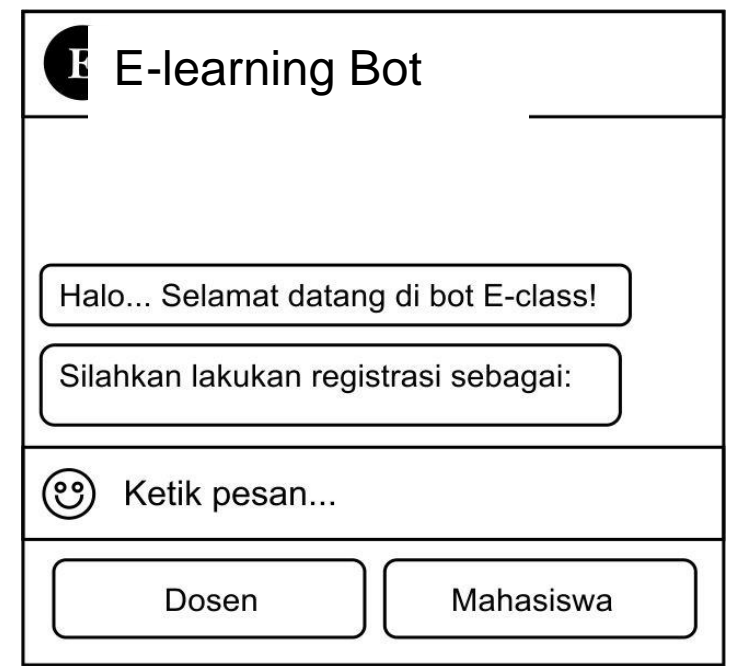

Gambar 8 Rancangan Antarmuka Fitur-fitur Mahasiswa

\section{HASIL DAN PEMBAHASAN}

\section{Website Admin}

Halaman ini merupakan halaman yang bertujuan untuk memberikan informasi secara umum mengenai jumlah dosen, jumlah mahasiswa, jumlah matakuliah, tugas dan materi dalam sistem. Pada bagian header terdapat tombol hamburger berguna untuk memperkecil bagian navigasi 
kiri dimana menu-menu ditempatkan, sehingga memperluas tampilan data yang terlihat. Berikut ditampilkan implementasi Halaman Beranda pada Gambar 10.

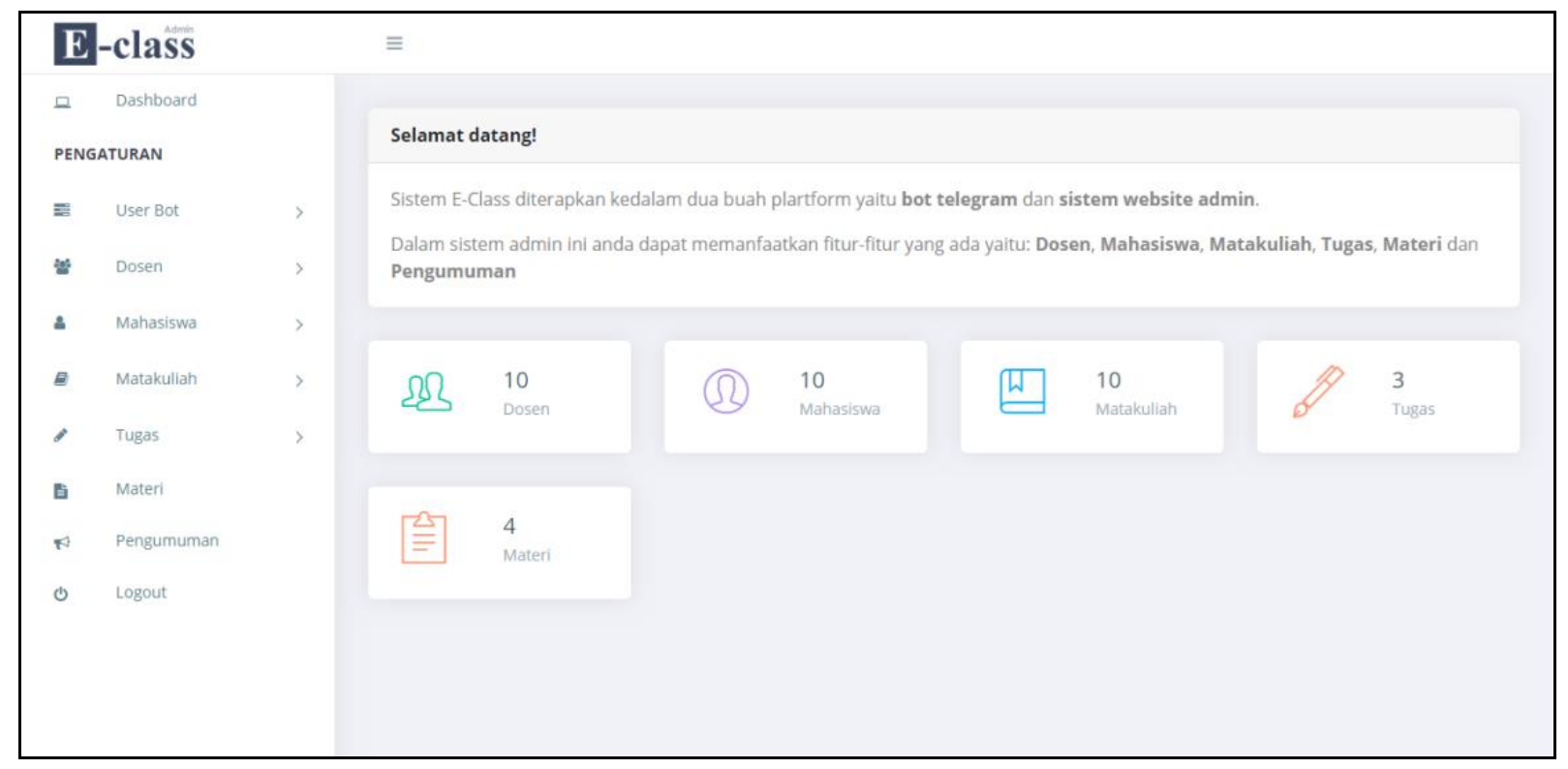

Gambar 9 Halaman Beranda

\section{Registrasi}

Registrasi dilakukan sebelum user dapat menggunakan fitur-fitur yang ada dalam bot. Terdapat pilihan untuk registrasi sebagai dosen atau mahasiswa. Berikut ditampilkan implementasi sistem Registrasi pada Gambar 11.

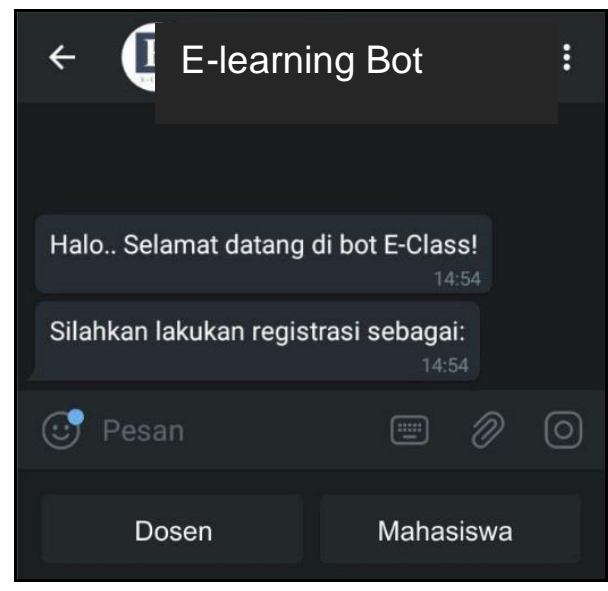

Gambar 10 Registrasi

\section{Fitur-fitur Dosen}

Bertujuan untuk memberikan tampilan menu dosen yaitu upload materi, upload tugas dan absensi. Berikut ditampilkan implementasi Fitur-fitur Dosen pada Gambar 12. 


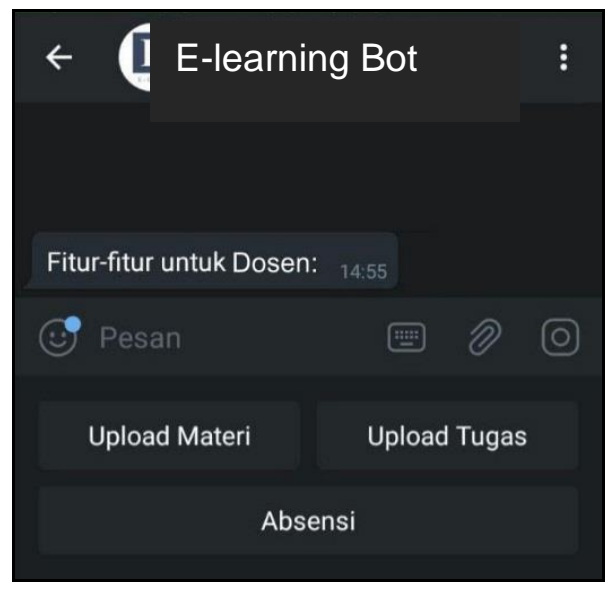

Gambar 11 Fitur-fitur Dosen

\section{Fitur-fitur Mahasiswa}

Bertujuan untuk memberikan tampilan menu mahasiswa yaitu download materi, download tugas dan pengumuman. Berikut ditampilkan implementasi Fitur-fitur Mahasiswa pada Gambar 13.

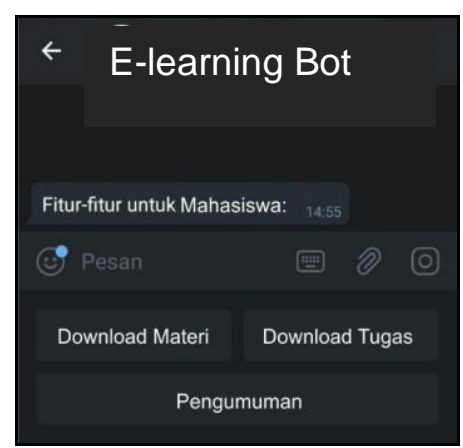

Gambar 12 Fitur-fitur Mahasiswa

\section{Pengujian Sistem}

Untuk menguji fungsionalitas dari sistem yang dibangun, penulis menggunakan teknik pengujian, dengan menggunakan metode blackbox testing. Dan setelah dilakukan 11 pengujian fitur menggunakan metode ini pada tabel 1 diperoleh kesimpulan semua fungsi sesuai dengan yang di rencanakan.

Table 1 Tabel Pengujian

\begin{tabular}{|c|l|c|c|c|}
\hline No & \multicolumn{1}{|c|}{ Fungsi } & Sub Fungsi & Pengujian & Kesimpulan \\
\hline 1. & Admin memiliki hak akses login & Login & Blackbox & Sesuai \\
\hline 2. & Mengakses Beranda (Dashboard) & - & Blackbox & Sesuai \\
\hline 3. & Mengelola Data User Bot & Hapus & Blackbox & Sesuai \\
\hline 4. & Mengelola Data Dosen & Tambah, Edit, & Blackbox & Sesuai \\
& & Hapus, Search & & Sesuai \\
\hline 5. & Mengelola Data Mahasiswa & Tambah, Edit, & Blackbox & \\
& & Hapus, Search & & \\
\hline
\end{tabular}




\begin{tabular}{|c|l|c|c|c|}
\hline 6. & Mengelola Data Matakuliah & $\begin{array}{c}\text { Tambah, Edit, } \\
\text { Hapus, Search }\end{array}$ & Blackbox & Sesuai \\
\hline 7. & Mengelola Data Tugas & $\begin{array}{c}\text { Hapus, Rekapan } \\
\text { Absensi, Search }\end{array}$ & Blackbox & Sesuai \\
\hline 8. & Mengelola Data Jawaban & Hapus, Search & Blackbox & Sesuai \\
\hline 9. & Mengelola Data Materi & Hapus, Search & Blackbox & Sesuai \\
\hline 10. & Mengelola Data Pengumuman & Tambah, Hapus, & Blackbox & Sesuai \\
\hline 11. & Admin melakukan logout dari sistem & Search & & Sesuai \\
\hline
\end{tabular}

\section{KESIMPULAN}

Berdasarkan pembahasan tentang penelitian Sistem E-learning Berbasis Website Dengan Telegram Bot, dapat diambil kesimpulan sebagai berikut:

1. Telah dihasilkan Sistem E-learning Berbasis Website Dengan Telegram Bot menggunakan dua platform yaitu sistem admin berbasis website dan bot telegram.

2. Sistem ini dibangun menggunakan Bahasa Pemrograman PHP dan basis data yang digunakan MySQL. Web server yang digunakan adalah Apache Web Server yang masih diakses secara offline (localhost).

3. Sistem admin memiliki fitur untuk mengelola data user (mahasiswa dan dosen), melihat dan menghapus materi, tugas, jawaban serta mengelola pengumuman yang nantinya dapat diterima seluruh mahasiswa.

4. Bot telegram memiliki fitur bagi dosen untuk meunggah materi, tugas dan melihat absensi serta mengunduh jawaban dari mahasiswa. Sedangkan bagi mahasiswa dapat mengunduh materi, tugas, mengunggah jawaban serta melihat list pengumuman. Sehingga sistem ini mempermudah proses belajar mengajar dalam kelas.

5. Pengujian sistem dilakukan dengan menerapkan metode blackbox testing dimana hasil yang diperoleh setelah pengujian memiliki kesesuaian dengan hasil yang diharapkan.

\section{DAFTAR PUSTAKA}

[1] A. Gumanti, . Yudiar, and . Syahruddin, Metode penelitian pendidikan. 2016.

[2] Musfiqon, "Pengembangan Media Dan Sumber Belajar," Jakarta PT. Prestasi Pusta Karya, 2012.

[3] M. S. Hanafy, "KONSEP BELAJAR DAN PEMBELAJARAN," Lentera Pendidik. J. Ilmu Tarb. dan Kegur., 2014, doi: 10.24252/lp.2014v17n1a5.

[4] J. T. Prasetya and A. Ahmadi, "Strategi belajar mengajar," Bandung CV, 2005.

[5] Y. Warisyah, "Prosiding Seminar Nasional Pendidikan Pentingnya 'Pendampingan Dialogis' Orang Tua Dalam Penggunaan Gadget Pada Anak Usia Dini,” Proseding Semin. Nas. Pendidik., 2015.

[6] M. K. Master, C. P. Kaur, A. Narasimhan, M. Nadeem, M. Ali, and R. B. Shaik, "Impact Of Electronic Gadgets On Psychological Behavior Of Middle School Children In UAE," Gulf Med. J., 2016.

[7] "POLA INTERAKSI SOSIAL SISWA PENGGUNA GADGET DI SMA N 1 SEMARANG," $J$. Educ. Soc. Stud., 2015, doi: 10.15294/jess.v4i1.6859.

[8] A. Cokrojoyo, J. Andjarwirawan, and A. Noertjahyana, "Pembuatan Bot Telegram Untuk Mengambil 
Informasi dan Jadwal Film Menggunakan PHP,’ J. Infra, 2017.

[9] G. Sastrawangsa, "Pemanfaatan Telegram Bot Untuk Automatisasi Layanan Dan Informasi Mahasiswa Dalam Konsep Smart Campus,” Konf. Nas. Sist. Inform., 2017.

[10] D. F. Murad, E. Fernando, M. Irsan, S. A. Murad, P. M. Akhirianto, and M. H. Wijaya, "Learning support system using chatbot in 'Kejar C Package' homeschooling program," 2019, doi: 10.1109/ICOIACT46704.2019.8938479.

[11] Epignosis, “e-learning Concepts, Trends, Applications,” Book, 2014.

[12] J. Williams, “Website,” British Journal of Occupational Therapy. 2002, doi: 10.4135/9781446215821.n234.

[13] N. Brugger, "Website history and the website as an object of study," New Media Soc., 2009, doi: $10.1177 / 1461444808099574$.

[14] I. P. Gede Abdi Sudiatmika, I. M. A. Wirahadi Putra, K. H. Santhi Dewi, and I. K. Budimas Aryawan, "Line Bot Implementation for Automation Balinese Language Dictionary," 2019, doi: 10.1109/ICORIS.2019.8874907.

[15] B. Web Studi Kasus Pondok Pesantren Al-Habi Sholeh Kabupaten Kubu Raya and K. Barat Yoki Firmansyah, "Penerapan Metode SDLC Waterfall Dalam Pembuatan Sistem Informasi Akademik," 2018.

[16] D. S. Budi, T. A. Y. Siswa, and H. Abijono, "Analisis Pemilihan Penerapan Proyek Metodologi Pengembangan Rekayasa Perangkat Lunak,” Teknika, 2017, doi: 10.34148/teknika.v5i1.48.

[17] W. S. Davis, D. C. Yen, and W. S. Davis, "Data flow diagrams," in The Information System Consultant's Handbook, 2020. 